\title{
Processo de Design Colaborativo de Artefatos Tangíveis para Crianças
}

\author{
Isomar Lima, Thais Castro, Adriana Dantas, Marcos Siqueira
}

Instituto de Computação - Universidade Federal do Amazonas (UFAM)

Av. Rodrigo Otávio, 3000 - 69077-000 - Manaus - AM - Brazil

\{isomar.slima, dricadoroteu\}@gmail.com, \{thais,mpsf\}@icomp.ufam.edu

\begin{abstract}
This paper presents a collaborative design process, based on interaction design for tangible learning artefacts, with a description of a design case of an artefact to help on middle schools' maths learning, the Tangible Tangram. On this experience, we made appropriation of techniques based on the approach Human Centred Design (HCD) where we worked with two levels of users: the maths teacher and the student. Student's profile (end user) is investigated considering which tasks he performs and where the interaction is more critical. In this way, the intermediate prototypes are evaluated in order to enhance the interaction (metacommunication) between students with the artefact and among students aiming at solving problems.
\end{abstract}

Resumo. Este artigo apresenta um processo de design colaborativo, baseado no design de interação para artefatos tangíveis para aprendizagem, contendo a descrição de um caso de design de um artefato para auxiliar na aprendizagem da matemática, o Tangram Tangível. Nessa experiência, nos apropriamos de técnicas da abordagem de Design Centrado em Humanos (HCD), trabalhando com dois níveis de usuário: o professor de matemática e o aluno. O perfil do aluno é investigado considerando quais atividades ele faz e onde a interação é mais crítica. Sendo assim, os protótipos intermediários são avaliados proporcionando, um maior potencial de interação entre os alunos com o objeto e entre os alunos entre si.

\section{Introdução}

Design de interação é um fator indispensável ao se desenvolver software interativos ou produtos [Oliveira, 2013] como: celular, videogame, impressora, guichê eletrônico, dentre outros. Define aspectos essenciais dos produtos interativos e questões durante os processos de design. Seu objetivo é redirecionar essas questões, trazendo um olhar crítico sobre avaliação utilizando as perspectivas de uso e comunicação para dentro do processo de design. Isto possivelmente é o motivo pelo qual tem sido objeto de estudo de diversas pesquisas relatadas na literatura.

O foco da pesquisa e do estudo em Design de Interação são as relações humanas estabelecidas através dos artefatos interativos, que funcionam também como meios de comunicação interpessoal, além de aspectos centrais referentes ao uso real e como são utilizados para a avaliação de produtos interativos [Barbosa; Silva, 2010]. É importante, então, que durante todo o ciclo do projeto de software ou artefato tangível, se observe o comportamento e a intenção dos diversos níveis de usuários e da própria equipe de design, confrontando e revendo os objetivos. 
Este artigo visa apresentar uma maneira de projetar artefatos tangíveis que o nosso grupo de pesquisa já vem utilizando ao longo de cinco anos. Essa maneira de projetar é inspirada no conceito de "Human Centred Design" (HCD), no qual os usuários dos artefatos são considerados como humanos, com desejos, mudanças de humor, variação na criatividade e atenção e etc. [Bevan, 1999]. Os métodos utilizados em HCD envolvem todas as pessoas da equipe na utilização do artefato, e não apenas o usuário final. Desses métodos, o que se aproxima mais com nossa maneira colaborativa de projetar artefatos tangíveis é o Design Participativo (DP) [Rosemberg et al, 2008].

Sendo assim, o processo que utilizamos é fortemente baseado no design participativo, mas em escala menor, com menos pessoas envolvidas. Desenvolvemos essa adaptação porque nossos projetos, em sua maioria, são voltados a crianças, com ou sem deficiência. Os projetos para crianças com deficiência ou inclusivos possuem especificidades próprias e constituem um subgrupo da maneira colaborativa de projetar artefatos para crianças.

Dessa forma, a adaptação do DP para o projeto de artefatos para crianças é discutida neste artigo com um cenário real de design de um artefato tangível, o Tangram, que consiste em um jogo com sete peças: um quadrado, um paralelogramo e cinco triângulos, formando um quebra-cabeça. A configuração geométrica de suas peças permite centenas de composições, tornando-o um material didático criativo no contexto de objetos concretos para auxiliar na aprendizagem de matemática.

É importante salientar que neste artigo utilizamos a palavra design no contexto de Interação Humano Computador (IHC), referindo-se ao processo inteiro de concepção e construção de algum artefato interativo, seja ele software ou hardware. Lawson [Lawson, 2006] define design como um processo em três etapas: análise da situação, síntese de uma solução (intervenção) e avaliação da nova situação.

Para que o design colaborativo descrito seja mais bem detalhado, esse trabalho está estruturado da seguinte forma: a Seção 2 apresenta uma descrição sobre a utilização de objetos concretos na Matemática e seu potencial como um objeto de aprendizagem tangível; a Seção 3 descreve a metodologia utilizada; a Seção 4 descreve a adaptação do DP para o processo de design colaborativo de artefatos para crianças utilizado; a discussão sobre os desdobramentos e implicações da proposta são discutidas na Seção 5.

\section{Objetos Concretos utilizados na Matemática}

Objetos concretos são utilizados no processo ensino-aprendizagem de matemática há muito tempo, embora haja novas propostas de utilização em sala de aula, conforme relatado nas pesquisas em [Guimarães e Rodrigues, 2015] e [Botas e Moreira, 2013]. Esses objetos visam diminuir a dificuldade dos alunos com operações e conceitos mais abstratos como frações, geometria plana, proporção e sistema de numeração decimal.

Algumas propostas como a de Guimarães e Rodrigues [2015] discutem as definições de objetos manipuláveis digitais a partir de materiais concretos já amplamente utilizados. Outros autores como [Einsenberg, 2003] discutem o conceito de artefatos tangíveis, em que esses artefatos representam uma oportunidade de criar sistemas físicos de modelagem computacionalmente aumentados, os quais contribuem tanto para os recursos digitais (editáveis) quanto no aspecto físico do modelo tangível. Entende-se por artefatos tangíveis, nesse contexto, interfaces ou objetos de interação do 
usuário, onde o mesmo manipula objetos físicos, para que haja modificações no meio digital.

Ao manipular artefatos tangíveis a criança se beneficia de algumas vantagens: relacionam novos conhecimentos com os que já sabiam, fazem e testam hipóteses, pensam onde aplicar o que estão aprendendo, expressam-se por meio de várias linguagens, aprendem novos métodos, novos conceitos, aprendem a serem críticos sobre os limites de aplicação dos novos conhecimentos. Para que isso ocorra, é necessário que esses objetos apresentem potenciais para boas interações, como uma boa aparência, e estejam inseridos em um ambiente computacional interativo, onde ferramentas para comunicação e cooperação sejam oferecidas para as crianças terem acesso ao registro de sua interação e às trilhas de aprendizagem que percorrem.

Para exemplificar, Zuckerman et al [2005] aponta os modelos de sistemas interativos direcionados para área da matemática com a utilização de artefatos tangíveis e objetos físicos (manipuláveis) que acompanham os efeitos do movimento da tela de computador. Portanto, no contexto desde trabalho, utilizamos um processo próprio de design colaborativo de um objeto manipulável amplamente utilizado em escolas, $\mathrm{o}$ tangram, o qual é descrito abaixo juntamente com o seu objetivo.

\subsection{Tangram}

O Tangram é um antigo jogo chinês com sete peças: um quadrado, um paralelogramo e cinco triângulos (dois grandes, dois pequenos e um médio), formando um quebracabeças. A configuração geométrica de suas peças permite centenas de composições, tornando-o um material didático criativo. É útil para desenvolver o raciocínio lógico e geométrico (habilidades de visualização, percepção espacial e análise das figuras) e exercitar as relações espaciais e as estratégias de resolução de problemas [Diniz, 2002].

Nossa proposta de intervenção para o tangram é uma solução envolvendo a divisão em camadas, formando um artefato multicamadas. Uma camada é a base, onde as peças do tangram são unidas. Nela há o processamento das informações obtidas pela manipulação das peças. Outra camada é das peças manipuláveis pelas crianças onde, ao serem manipuladas, as mesmas fornecem feedback ao professor e aos próprios alunos, positivos ou negativos, informando se foram agrupadas corretamente. Por último, há a camada do software representada pelo App que se comunica com as peças manipuláveis por meio de bluetooth, gerando logs com o registro das manipulações dos alunos ao jogarem, fornecendo assim trilhas de aprendizagem que, posteriormente, podem ser utilizadas pelos professores para aferir a aprendizagem de cada aluno.

O Tangram Tangível pode ser utilizado em atividades individuais ou em pequenos grupos. Essas atividades são, basicamente, de dois tipos: encaixar todas as peças corretamente na moldura quadrada e montar as peças de forma a reproduzir figuras pré-definidas. Mas o professor pode incrementar essas atividades em conjunto com as funcionalidades do App, pedindo o cálculo da medida de algum lado da figura montada, a identificação de determinadas figuras escondidas nas demais, etc. A Figura 1 ilustra algumas construções básicas do Tangram, em especial quatro maneiras diferentes de montar uma casa com as peças. 


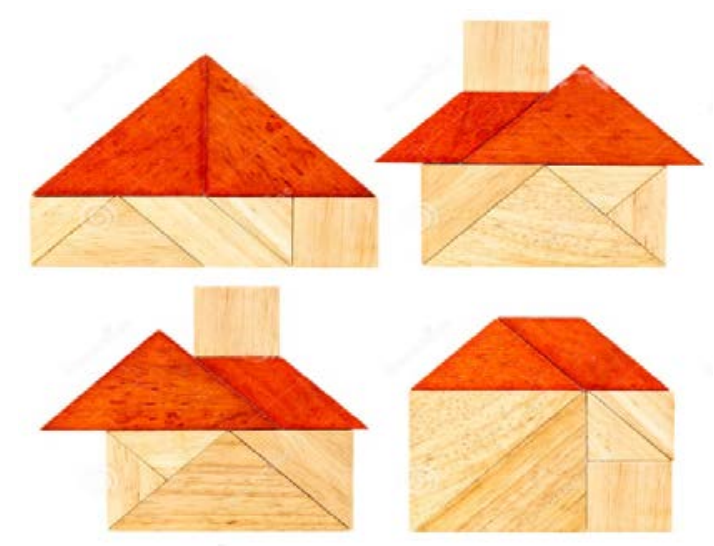

Figura 1 - Modelos de Casa no Tangram. Fonte: Diniz, 2002.

No jogo Tangram é possível aprender conceitos geométricos de frações, lado correspondente, ângulo correspondente, formatos semelhantes, área e perímetro de figuras planas, proporcionalidade entre os lados dos triângulos, ângulos congruentes, polígonos congruentes e semelhantes formados pelas peças do jogo [Genova, 2005]. Esses conceitos fazem parte do conteúdo de geometria trabalhados tanto nas séries iniciais quanto nas finais do ensino fundamental, em profundidades diferentes.

\section{Metodologia}

Visando obter um olhar sobre os usuários, considerando seu próprio contexto, adotamos o design centrado no ser humano (HCD)[Maguire, 2001], onde se considera as mudanças de desejos, intenções e atenção inerentes a cada ser humano. Das diversas perspectivas adotadas em IHC ao longo dos anos, esta nos possibilitou um contato permanente com os usuários e stakeholders, como algumas crianças, professores de matemática e designers com perfis diferentes. Portanto, nossa equipe de design é composta por um professor de matemática do ensino fundamental, um aluno de graduação com experiência em desenvolvimento com arduino, duas crianças para os testes formativos e a professora orientadora e o próprio autor como designer principal e gerente do projeto. O professor de matemática, que mantém contato constante com os alunos do $6^{\circ}$. ano do Ensino Fundamental, testa algumas hipóteses de cenários de interação com o tangram tradicional com esses alunos, fornecendo feedback ao restante da equipe de design.

Como metodologia de projeto e desenvolvimento (design), adotamos o Design Participativo e fizemos pequenas adaptações em processos específicos. A adaptação principal se deu principalmente pela dificuldade de manter crianças como participantes da equipe de design. Como se trata de um objeto de aprendizagem, se as crianças fizessem parte do design estariam contaminadas pelo estilo de abordagem para geometria e acabariam se adaptando ao tangram tangível e não o contrário, pois em geral, elas são muito boas em perceber padrões em jogos.

Em termos de pesquisa, sua natureza é aplicada, uma vez que buscamos desenvolver o artefato tangível para utilizá-lo como auxiliar na aprendizagem de 
matemática. Visando coletar os dados sistematicamente para encontrar padrões, a pesquisa adquiriu uma natureza mais qualitativa, uma vez que também procuramos compreender o fenômeno, ou seja, o processo de aquisição de expertise em resolver problemas geométricos com o tangram. Quanto aos objetivos, propomos essa pesquisa utilizando o DP adaptado para o design de artefatos tangíveis com crianças. O Tangram Tangível é, então, uma pesquisa explicativa, em que utilizaremos nos testes com os usuários tanto o método experimental quanto o observacional para analisar as outras variáveis emocionais e de contexto que podem influenciar o desempenho.

Em vista da caracterização do design para crianças, exemplificado aqui com o design do Tangram Tangível exposto acima, o nosso processo de design pode ser descrito através de um modelo de processo de negócios utilizando BPMN, conforme ilustra a Figura 2.

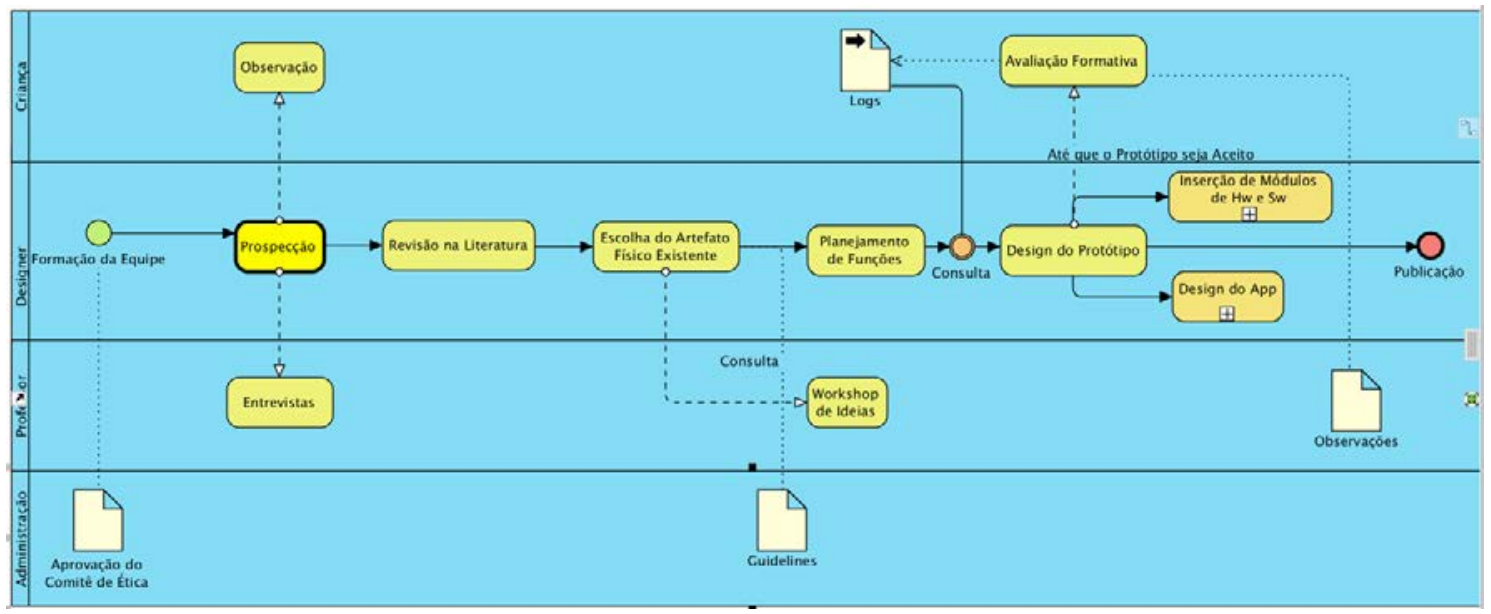

Figura 2 - Processo de Design em Artefatos Tangíveis para Crianças

O processo acima foi definido com base na definição de processos de design para artefatos tangíveis descritos em [Bakker, Antle e Van Den Hoven, 2012] e [Kameas, 2005]. A síntese dessas definições genéricas para design são:

1. Estudo inicial para levantamento de metáforas de incorporação aos objetos e legislação - nessa atividade, ao envolver design de artefatos compostos por um objeto concreto de aprendizagem já existente, deve-se analisar a intenção da interação na criação de um artefato em software. Nesse caso, uma investigação contextual sobre as funcionalidades para a aplicação específica pode ser obtida com a incorporação de elementos de hardware.

2. Criação de protótipos de baixa fidelidade baseados nas metáforas para exploração de entradas no espaço de design - juntamente com stakeholders, definir o tamanho e o espaço adequado para manipulação do objeto. Essa fase, quando o artefato é uma adaptação de um artefato manipulável já existente, pode ser realizada utilizando-se o próprio artefato existente e testando diferentes estratégias de uso que somente com a presença dos stakeholders é possível ser realizada.

3. Avaliação dos protótipos de baixa fidelidade para validar as entradas em termos de affordances para manipulação dos artefatos. Segundo [McGrenere and Wayne, 2000] as affordances podem ser definidas como as relações entre um objeto, um 
ambiente e um organismo que, com um conjunto de estímulos, fazem o organismo interagir com o objeto. No caso do Tangrem Tangível essas relações possibilitam ao usuário identificar as funcionalidade do Tangram sem a necessidade prévia de explicação já que por ser um jogo geométrico facilita a intuição. Uma vez definidas as entradas na etapa anterior, procede-se a avaliação formativa ainda nesses estágios iniciais, com especial atenção para as affordances e diferenças de meaning making ou processo de aquisição de sentido para os designers, professores e alunos.

4. Criação de protótipos interativos de alta fidelidade com affordances apropriadas nessa fase os protótipos já estão com o hardware e software definidos para possibilitar uma melhor interação entre os elementos do artefato e entre as crianças.

5. Avaliação dos protótipos de alta fidelidade - procede-se a avaliação até que um teste de aceitabilidade forneça resultados positivos.

No processo descrito na Figura 2 observamos as etapas de desenvolvimento de protótipos tangíveis utilizadas por pesquisas na área (descritas acima) e adaptamos ao nosso contexto real de aplicação, que é o desenvolvimento de artefatos tangíveis para crianças caracterizados como objetos educacionais tangíveis no domínio da matemática.

$\mathrm{Na}$ faixa principal do processo que definimos, as tarefas envolvendo formação de equipe, prospecção e revisão da literatura correspondem à fase 1; as tarefas de escolha do artefato físico existente e planejamento de funções correspondem à fase 2; definimos como avaliação formativa a tarefa de selecionar e aplicar métodos de avaliação da interação conhecidos, tanto para protótipos de baixa quanto de alta fidelidade, correspondendo de forma incremental às fases 3 e 5 ; e consulta aos logs existentes em uma base de dados em conjunto com o design do protótipo, correspondendo à fase 4. Esse processo só termina com a publicação do protótipo aceito, após um conjunto de testes com crianças.

\section{Desenvolvimento do Protótipo}

Seguindo o processo de design descrito na Figura 2 para o caso de design Tangram Tangível, houve uma articulação entre diferentes perfis para compor o time de desenvolvimento. Isso envolveu a participação de um professor de matemática da segunda etapa do ensino fundamental da rede pública de ensino local, duas crianças que, apesar de não testarmos diretamente os protótipos iniciais com elas, forneceram feedback prático sobre o uso do tangram utilizado em sala de aula, e os membros da equipe responsáveis pela parte técnica de desenvolvimento dos protótipos. Essa última subequipe, representada na figura 2 como Designer, é composta por um aluno de graduação em Ciência da Computação cujo papel interno é de desenvolvedor do App, a professora orientadora que atua como gerente e dois alunos de mestrado, um atuando na concepção e implementação das ideias definidas e outro na concepção das avaliações formativas.

Os instrumentos iniciais de entrevista e observação foram aplicados com o professor e as duas crianças participantes da equipe para definição das affordances e funcionalidades desejáveis para o protótipo. Na revisão da literatura foram encontrados trabalhos com desenvolvimento de protótipo para outros domínios, os quais utilizamos como uma comparação para as técnicas definidas e orientaram a própria escolha do artefato de aprendizagem da matemática. Orientando essa escolha também foi realizado o workshop de ideias com todos os envolvidos, mas de forma prática, com atividades de 
composição de figuras no tangram. O planejamento das funcionalidades do tangram, além de receber os subsídios das tarefas anteriores, consultou alguns conjuntos de guidelines para desenvolvimento de artefatos tangíveis, os quais apresentaremos na subseção a seguir.

Para o primeiro protótipo funcional, definido após o workshop de ideias, definimos os materiais a serem utilizados, que foram: Arduino Uno, Jumper wires, USB Cable, LED, Tecido inteligente, Cartolina, Emborrachado, Papelão Branco, Régua, Lápis, Pincel e Fitas. Nesse protótipo inicial projetamos um quadrado grande com os desenhos das peças do tangram em forma da figura de uma casa, que serviria como base para testar as funcionalidades com as luzes de LED e sensores via tecido condutivo. Realizamos uma avaliação formativa com teste exploratório por todos os integrantes da equipe do projeto. Como o protótipo atendeu às expectativas e as funcionalidades atendidas, passamos para o outro protótipo, dessa vez um que pudesse também atender às affordances.

Os materiais para o segundo protótipo foram quase todos os mesmos, somente acrescentamos o shield Bluetooth e o sensor hall. Os componentes utilizados, então, foram: Arduino Uno, Sensor Hall, Shield Bluetooth, Jumper wires, USB Cable, LED, Tecido inteligente, Cartolina, Emborrachado, Papelão Branco, Régua, Lápis, Pincel e Fitas. Foram feitas as marcações para cada sensor hall nas 7 peças que compõem o Tangram e toda a etapa de acabamento das peças. Cada peça recebeu um Arduino Uno e um Shield Bluetooth para fazer comunicação com o Arduino servidor que por vez comunica-se com o dispositivo Android. Isso é ilustrado pela Figura 3, que mostra as marcações e pela Figura 4 que mostra a composição da peça.

As Figuras 5 e 6 ilustram as peças do tangram já com os Arduinos e sensores embutidos. Os materiais escolhidos são leves, o que torna a affordance melhor. A base do tangram, onde ele é montado foi recortada como uma primeira tentativa de explorar e combinar as diferentes possibilidades de manipulação. Segundo os resultados de nossa avaliação formativa para essa etapa, ainda realizada com a própria equipe do projeto, definimos que no próximo protótipo, já a ser manipulado por quarenta crianças em um contexto real de uso, a base será fixa, detectando as peças por mapeamento de região ocupada por cada uma.

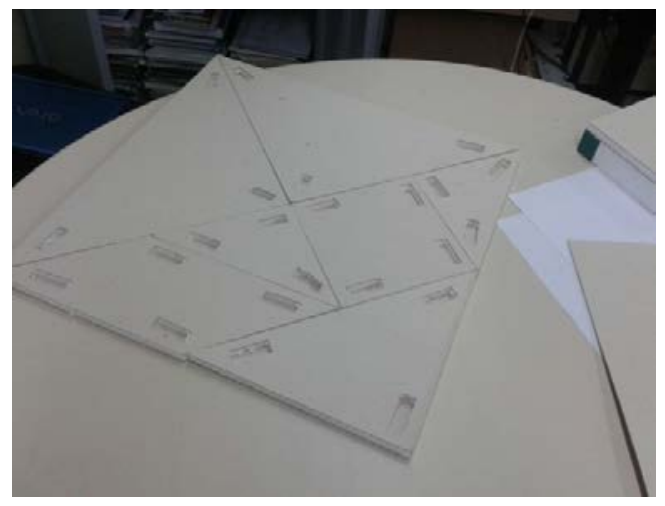

Figura 3. Marcações para os sensores hall.

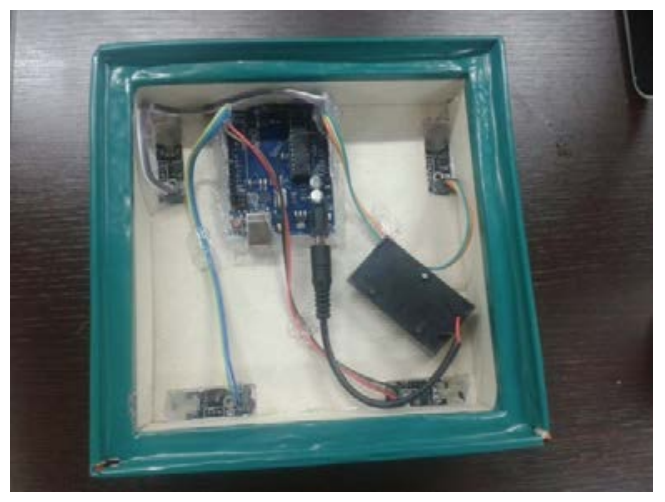

Figure 4. Peça quadrada com sensores hall e Arduino. 
Consideramos também os guidelines existentes na literatura para desenvolvimento de múltiplos artefatos tangíveis [Zuckerman et al., 2016], [Heijboer, Marigo, e Van Den Hoven , 2008], [Kameas et al., 2005] e [Chu, 2015]. Desses trabalhos, o guideline mais completo e significativo foi o descrito por [Antle, Alissa N., e Alyssa F. Wise, 2013], sintetizado na Tabela 1.

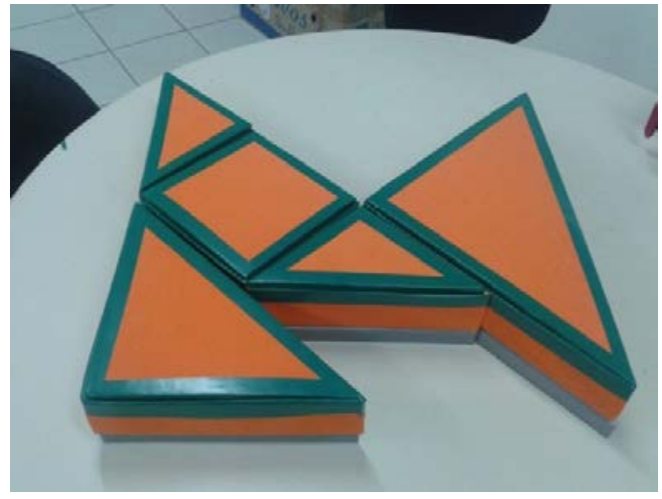

Figura 5. Peças triângulos e quadrado com sensores hall, Módulo NRF24L01 e Arduino.

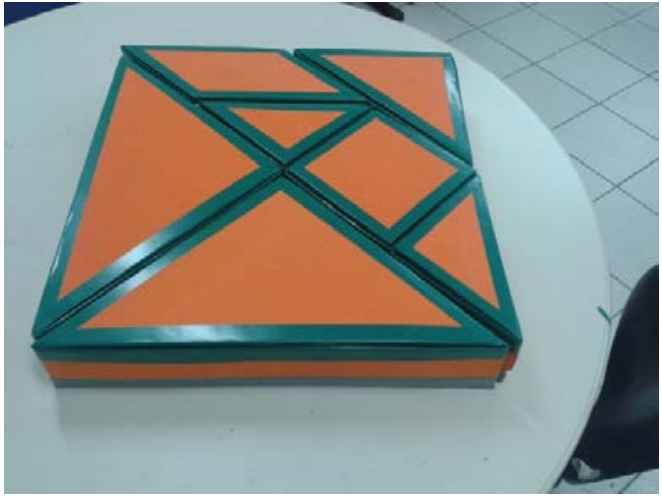

Figura 6. Peças Tangram finalizadas com sensores hall, Módulo NRF24L01 e Arduino.

Tabela 1 - Guidelines para Interfaces Tangíveis para Usuários.

Fonte: por [Antle, Alissa N., e Alyssa F. Wise, 2013].

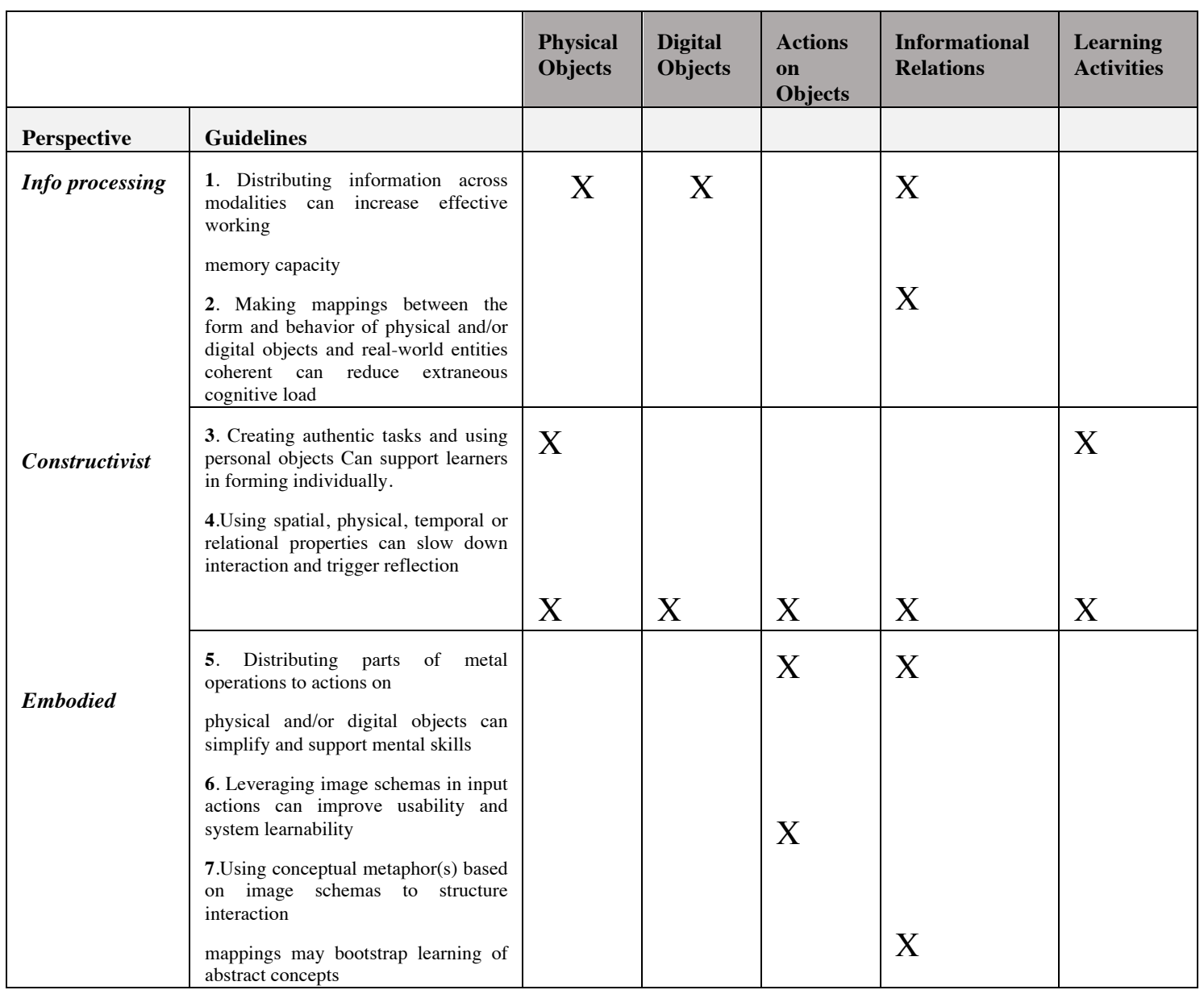




\begin{tabular}{|c|c|c|c|c|c|c|}
\hline Distributed & $\begin{array}{l}\text { 8. Designing objects that allow spatial } \\
\text { reconfiguration } \\
\text { can enable mutual adaptation of ideas } \\
\text { 9. Using concrete representations can } \\
\text { support interpretation of symbolic } \\
\text { representations of abstract concepts }\end{array}$ & $X$ & X & & $\mathrm{X}$ & \\
\hline Collaborative & $\begin{array}{l}\text { 10. Creating configurations in which } \\
\text { participants can monitor each other`s } \\
\text { activity and gaze can support the } \\
\text { development of shared } \\
\text { understandings } \\
\text { 11. Distributing roles, information and } \\
\text { controls across the TUI learning } \\
\text { environment can promote negotiation } \\
\text { and collaboration } \\
\text { 12.Creating constrained or } \\
\text { codependent access points schemes } \\
\text { can compel learners to negotiate with } \\
\text { each other }\end{array}$ & $X$ & $X$ & $X$ & & X \\
\hline
\end{tabular}

As guidelines para objetos físicos e digitais, correspondentes às categorias processamento de informação, construtivista e distribuída estão contempladas em nosso processo de design colaborativo de artefatos tangíveis para crianças (Figura 2). As que correspondem a incorporadas e colaborativas são explicadas abaixo:

(i) Partes distribuídas de operações mentais para ação em objetos podem simplificar e fornecer suporte às habilidades mentais - isso é atingido na especificação das atividades a serem realizadas com o protótipo, algumas das quais já definidas para a avaliação em situação real de uso.

(ii) Nivelamento de esquemas de imagem em ações de entrada podem melhorar a usabilidade e aprendizagem do sistema - as imagens da operação desejada é mostrada no App para que a criança reflita sobre sua composição e a materialize no objeto físico. A imagem que vê no App é a que vai formar com as peças.

(iii) Uso de propriedades físicas, espaciais, temporais e relacionais podem diminuir a interação e aumentar a reflexão - esse é um equilíbrio que procuramos obter na especificação das tarefas. Uma será de construção de imagem, outra de observação de uma figura construída para reflexão e outra envolvendo dedução de medidas. Tudo isso verificado automaticamente pelo artefato Tangram Tangível.

(iv) Criação de configurações que possibilitem que as pessoas visualizem suas atividades e as dos demais - para isso, desenvolvemos uma funcionalidade para registro dos logs e utilizamos uma ferramenta de visualização gráfica como plugin.

(v) Distribuição de papéis, informação e controle através dos artefatos nos ambientes de aprendizagem podem promover negociação e colaboração - atividades em grupo proporcional isso. O protótipo (App e físico) possibilita a materialização dessas estratégias fornecendo registro individual e em grupo, de acordo com a atividade e, posteriormente identificação das trilhas de aprendizagem no registro dos logs (erros e acertos), vídeos e anotações.

(vi) Criação de um esquema de pontos de acesso restrito e co-dependente podem estimular os aprendizes a negociar entre si - temos somente um artefato físico 
tangram. Portanto, nas atividades em grupo, as crianças terão que negociar para gerarem as soluções.

\subsection{Criação do aplicativo para o Tangram Tangível}

Para esta tarefa, um dos pontos mais importantes foi o planejamento do conteúdo da aplicação que teve como foco conhecer e entender o público-alvo e o seu nível de instrução.

Após se ter um entendimento completo de quem é o público-alvo (conhecimento proveniente das primeiras tarefas do processo da Figura 2) e como ele pensa e reage, deu-se início ao design do App. Esse processo começa com a decisão sobre o que se quer comunicar e os meios que se pretende usar para transmiti-lo. A Figura 7 mostra algumas telas do App desenvolvido.

Durante o design do App levou-se em conta não apenas ilustrações de alta qualidade, mas também a escolha apropriada de estilos, para se obter uma comunicação eficaz já que imagens, gráficos e ilustrações refletem a emoção mais rapidamente do que palavras. No entanto, deve-se tomar muito cuidado com este tipo de recurso, já que podem transmitir uma mensagem diferente da que se pretende e também para que não se torne algo cansativo para o usuário [Wolfgram, 1994].
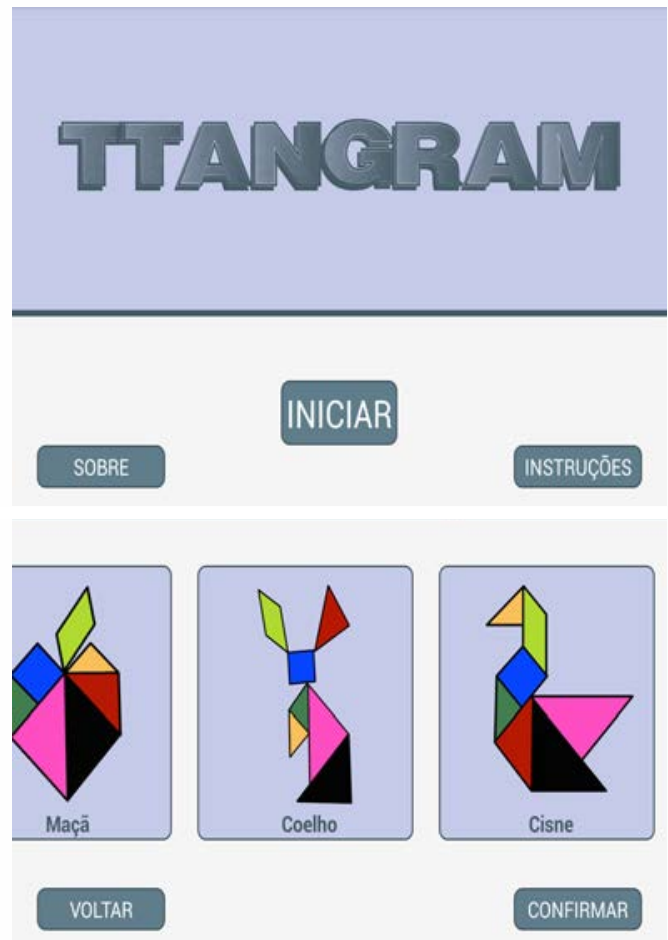

CONFIRMAR
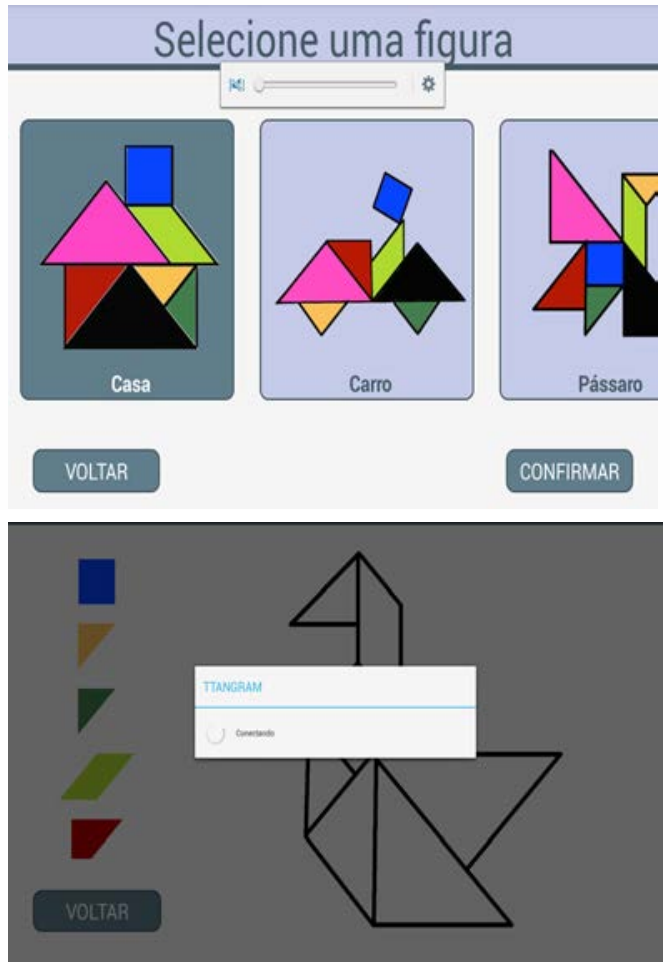

Figure 7 - Telas do App

Ao longo do design do App, além do planejamento do conteúdo, foram considerados os aspectos técnicos tais como: objetivos pedagógicos que podem ser classificados em tutoriais, aplicativos, programação, aplicativos, exercícios e prática, 
multimídia e Internet, simulação, modelagem e jogos [Valente, 1999]. O software aqui descrito classifica-se como aplicativo e jogo. Outro aspecto focado foi a interação, pois este aspecto em Apps traz à tona um novo nível de controle implícito. O uso apropriado da interatividade resulta na efetiva lembrança da mensagem por parte do usuário [Wolfgram. 1994], pois as pessoas lembram mais daquilo com que interagem.

\section{Especificação para objetos de aprendizagem tangíveis}

Com base em recomendações e guidelines já mencionados nas seções acima, definimos algumas especificações para criação de artefatos tangíveis utilizados como objetos de aprendizagem:

- Possuir dimensões e/ou o peso aceitáveis: não podem ser nem muito pesados nem muito leves para que atendem ao requisito de affordance.

- Fornecer ideias multissensoriais para contemplar diferentes estilos de aprendizagem e necessidades diversas: essas ideias ou representações devem permitir que outros sentidos das crianças sejam empregados nas atividades, ajudando-as a raciocinar. O objetivo é oferecer oportunidades de interação entre as crianças, favorecendo assim a exploração com mais liberdade das figuras geométricas, seus perímetros, áreas e ângulos.

- O produto deve ser resistente, de forma que as crianças não tenham receio de quebrar na hora de brincar (manipular): as bases para interfaces tangíveis devem ser feitas de materiais firmes tais como madeira, plástico ou papel madeira. Suas extremidades devem possuir cantos arredondados usados para definir uma transição plana entre duas faces, normalmente definida a partir de uma aresta do modelo sólido ou de faces. A parte eletrônica do objeto deve ficar embutida para que não haja contato físico da criança.

- Ser manipulável (móvel e independente): o objeto tangível deve ser independente de energia com uso de baterias permitindo a exploração, construção e divisão de formas geométricas. A interface tangível deve continuar sendo usada para que as crianças possam explorar as especificidades para a qual a mesma foi desenvolvida mesmo com os recursos eletrônicos desativados.

- Feedback: Deve possuir uma opção de ajuda e possuir feedback positivo e negativo. Segundo Kekalainen (2005): Os métodos de aquisição do feedback dos usuários podem ser divididos em duas categorias:

a) Implícito: realizado pelo sistema, baseando-se em informações adquiridas indiretamente dos usuários, como histórico de navegação, cliques, entre outros;

b) Explícito: realizado pelos usuários, baseando-se em informações diretas do usuário, como a indicação de pertinência de um resultado, por exemplo, nos sistemas que possuem algum mecanismo de feedback explícito, a indicação da relevância dos resultados pode ser binária, quando apenas é dito se o resultado é relevante ou não, ou em escala, quando existem alguns níveis (mais que dois) de relevância possíveis a serem escolhidos. Essa escala pode ser efetuada usando números (de 1 à 5 , por exemplo), letras ou com descrições ("irrelevante", "pouco relevante", "relevante", "muito relevante", por exemplo).

- Estímulo ao raciocínio: Provendo reflexão do pensamento logico na resolução dos problemas abordados pelo conteúdo e o objetivo principal da interface. 
- Independência do tutor: A interface deve proporcionar aos alunos (crianças) uma certa independência do tutor ou professor, para que a mesma consiga realizar algumas atividades de forma independente (sem ajuda externa), oferecendo segurança à criança durante a execução da atividade, motivando-a a explorar suas funcionalidades.

- Ligação entre teoria-prática: interfaces e artefatos tangíveis para crianças devem ser intuitivas e lúdicas, a exemplo das atividades de montagem comuns em brincadeiras infantis e atividades escolares.

- Permitir uso colaborativo: artefatos tangíveis devem oferecer aos seus usuários diferentes formas de interação, facilitando o controle, a coordenação, a colaboração e a comunicação entre as partes envolvidas. Dessa forma, as soluções são criadas com negociação e colaboração, desde o início da atividade.

- Flexibilidade para criação de atividades: os artefatos de hardware e software tangíveis devem possibilitar a mudança e implementação de novas atividades pelos professores e tutores sem maiores traumas de uma maneira muito simples.

- Adaptação do protótipo (material) aos conteúdos: as configurações devem ser adaptáveis aos conteúdos propostos pelos professores.

Interface compreensível: uma interface tangível deve ser fácil de usar. $\mathrm{Na}$ interface do Tangram Tangível o professor escolhe o nível de dificuldade e a figura que a criança irá montar e o tipo de atividade ou pode recorrer ao menu de ajuda em caso de dúvidas e consultar maneiras de configurar novas propostas de uso.

As especificações acima estão em fase de formalização para que possam ser reutilizadas por outros pesquisadores e professores que precisem definir um objeto de aprendizagem tangível para a aprendizagem de matemática. Conforme mencionado anteriormente, as especificações acima foram definidas com base nas guidelines descritas em [Zuckerman et al., 2016], [Heijboer, Marigo, e Van Den Hoven, 2008], [Kameas et al., 2005] e [Chu, 2015], utilizando como princípio a avaliação formativa que, segundo [Araújo e Soares, 2014] possibilita verificar problemas de interação e de interpretação de interface durante o processo de design de um artefato.

Atualmente o protótipo está sendo preparado para a avaliação em uma situação real de uso, em uma gincana de matemática a ser realizada com cerca de quarenta crianças do $6^{\circ}$ ano do ensino fundamental de uma escola da rede pública de ensino local. Durante essa gincana, os $\log s$ serão armazenados para compor a base inicial de logs relacionados a atividades, já ficando disponíveis para visualização. Após a gincana, será realizada uma análise quantitativa dos resultados, considerando os itens que definem uma boa interação com objetos tangíveis e identificação das trilhas de aprendizagem individuais e em grupo.

\section{Conclusão}

Interfaces tangíveis agregam valor a objetos computacionais (software), possibilitando que haja mais interação entre os usuários e o registro das interações dos usuários com os artefatos, possibilitando abordagens diferenciadas para as necessidades específicas dos usuários.

Conforme exemplificado pelas referências neste trabalho, existem várias interfaces tangíveis propostas para a área educacional. Sabe-se que design de interfaces interativas não é mais exclusivamente gráfico, mas também envolve forma e materiais. 
Assim, características como ergonomia, peso, textura e outros aspectos ligados a materiais físicos compõem novas dimensões para projeto e avaliação de interfaces [Cardador, 2013]. Neste trabalho, baseados em nossas experiências anteriores, nas recomendações, guidelines e abordagens encontradas na literatura, propomos um processo de design colaborativo de artefatos tangíveis para crianças. Descrevemos seu funcionamento através da prototipação de um caso de design, o Tangram Tangível, o qual é voltado para auxiliar na aprendizagem da matemática, abordando especificamente o conteúdo de geometria plana.

Juntamente com a prototipação do Tangram Tangível, neste artigo definimos uma especificação para objetos de aprendizagem tangíveis no contexto de aprendizagem de matemática na educação básica. Essa especificação está em processo de formalização para ser disponibilizada para a configuração de novos artefatos para o mesmo propósito e ser usada também para configurar novas atividades em um sistema de gerenciamento de objetos educacionais tangíveis.

A preparação de um bom material e a forma como são organizados na sala induz o aluno à manipulação imediata dos objetos (alta affordance), sem a necessidade de leituras longas e cansativas. Entretanto, ao utilizar esse tipo de tecnologia em uma sala de aula real, o professor deve proceder um planejamento minucioso, o que requer tempo e habilidade do professor na utilização dos artefatos.

\section{Agradecimentos}

Esse trabalho recebeu apoio da FAPEAM - Projeto "Intelligent Framework to Support Collaboration", Ed. 016/2013, Res. 035/2013. Agradecemos aos alunos de graduação e pós-graduação, professor e crianças que participam da equipe de design. Agradecemos também a CAPES, através do projeto CAReCO - Sistemas de Recomendação para Manutenção Colaborativa de Software, aprovado sob o edital n. 071/2013, o qual possibilitou algumas definições deste artigo, via trocas de ideias.

\section{Referências}

Antle, Alissa N. and Wise, Alyssa F. "Getting down to details: Using theories of cognition and learning to inform tangible user interface design." Interacting with Computers 25.1 (2013): 1-20.

Araújo, Eduardo Cruz, and Luiz Fernando Gomes Soares. "Designing iDTV Applications through Interactive Storyboards." Proceedings of the 20th Brazilian Symposium on Multimedia and the Web. ACM, 2014.

Bakker, Saskia; Antle, Alissa N. and Van Den Hoven, Elise. "Embodied metaphors in tangible interaction design." Personal and Ubiquitous Computing 16.4 (2012): 433449 .

Barbosa, J, D, S., Silva, S, B. Interação Humano Computador. Editora Campus, Elsevier Editora, Rio de Janeiro - RJ- Brasil, 2010.

Bevan, N., Curson, I. Planning and Implementing User-Centred Design. Teddington, Middlesex, TW11 0DU, UK, CHI 99 15-20 MAY 1999.

Chu, Jean Ho. "Designing Tangible Interfaces to Support Expression and Sensemaking in Interactive Narratives." Proceedings of the Ninth International Conference on Tangible, Embedded, and Embodied Interaction. ACM, 2015. 
Cardador, D.; Ugulino, W.; veja, K.; Filippo, D.; Raposo, A.; Fuks, H. Uma abordagem sistemática de prototipação colaborativa para a criação de tangíveis. In: Simpósio Brasileiro De Sistemas Colaborativos (SBSC'13), 5., 2013, Manaus, Brasil. Anais... Manaus: SBC, 2013.

Diniz, I, M,; et. Al. A matemática das sete peças do tangram. CAEM-IME/USP, 2002.

Einsenberg, M. Mindstuff: Educational Technology beyond the computer. Convergence, Colorado-USA, 2003.

Genova, A. C. Brincando Com Tangram e Origami. Editora Global-São Paulo - 2005, Edição: 4 , Vol. 18.

Heijboer, Marigo, and Elise Van Den Hoven. "Keeping up appearances: interpretation of tangible artifact design." Proceedings of the 5th Nordic conference on Humancomputer interaction: building bridges. ACM, 2008.

Kameas, Achilles, Irene Mavrommati, and Panos Markopoulos. "Computing in tangible: using artifacts as components of ambient intelligence environments." Ambient Intelligence (2005): 121-142.

Kekalainen, J. (2005). Binary and graded relevance in IR evaluations - comparison of the effects on ranking of IR systems. In: Information Processing and Management: an International Journal, v.41 n.5, p.1019-1033. International Journal, v.41 n.5, p.1019-1033, 2005.

Kitchenham, B. Dyba, T. Jorgensen, M. Evidence Based Software Engineering, In Proceedings of 26th International Conference on Software Engineering (ICSE'04), pp 273-281, 2004.

Lawson, Bryan. How designers think: The design process demystified. Routledge, 2006.

Maguire, Martin. "Methods to support human-centred design." International journal of human-computer studies 55.4 (2001): 587-634.

McGrenere, Joanna, and Wayne Ho. "Affordances: Clarifying and evolving a concept." Graphics Interface. Vol. 2000. 2000.

Oliveira, G. C. C. vamos fazer design de interação? ilustração e diagramação: estúdio grampo, 2013. http://designdeinteracao.com.br/wp/wpcontent/uploads/2013/10/vfdi.pdf.

Rosemberg, C., Schilling, A., Bastos, C., Araripe, R. Prototipação de Software e Design Participativo: uma Experiência do Atlântico. 21-24 Outubro I Porto Alegre - RS, Brasil, 2008.

Valente, J, A. (Org) - O computador na sociedade do conhecimento. Campinas, SP: Unicamp/NIED, 1999.

Wolfgram, E. D. Criando Em Multimídia. Editora Campus, Edição 87, Rio de Janeiro- RJ, Dezembro de 1994.

Zuckerman, O. S. A., Resnick, M. Extending tangible interfaces for Education: Digital Montessori-inspired manipulatives. In Proceesings of the SIGCHI Conference on Human Factors in Computing Systems (CHI 05), pages 859-868, Portland, USA. ACM Press. 2005. 
Zuckerman, O., Gal, T., Keren-Capelovitch, T., Karsovsky, T., Gal-Oz, A., \& Weiss, P. L. T. (2016, February). DataSpoon: Overcoming Design Challenges in Tangible and Embedded Assistive Technologies. In Proceedings of the TEI'16: Tenth International Conference on Tangible, Embedded, and Embodied Interaction (pp. 30-37). ACM. 